\title{
Static, Dynamic and Modal Analysis of Micromilling Table
}

\author{
R R Honkalas ${ }^{1}$, M L Kulkarni ${ }^{2}$, B B Deshmukh ${ }^{3}$ \\ ${ }^{\text {I}}$ (Mechanical Engg.Department, N B N Sinhgad college of Engg. Solapur, Solapur University, India) \\ ${ }^{2}$ (Mechanical Engg.Department, MITAOE, Alandi, Pune, Pune University, India) \\ ${ }^{3}$ (Mechanical Engg.Department, WIT, Solapur, Solapur University, India)
}

\begin{abstract}
Mechanical micro machining is an ideal method to produce high accuracy micro components and micro-milling is the most flexible enabling process and is thus able to generate a wider variety of complex micro components. Machine table is one of the key element of micro-milling machine. Most of Micro milling table consist of slides/guides, recirculating ball screw and air bearing. In most the linear motion guides are used for accurate linear movements. While studying the literature available on micro-milling, there is little information available on mechanical structure like linear motion guide required for the machine to meet desired accuracy and therefore detail study of the table of micro-milling is required. This work attempts to complete study of table for micro-milling within frame work of FEA, in order to assure the desired performance of micromilling machine. However, no systematic design and analysis procedure is available / reported before in the available literature. Finite Element Analysis of Micromilling table is carried out on Static Stress Analysis (Von Mises Analysis), Dynamic Analysis and Modal Analysis aspects of analysis to evaluate the response of micromilling table. In this attempt the response of micromilling table has obtained in the form of frequency, amplitude, compliance and stiffness.
\end{abstract}

Keywords: Dynamic, FEA, Modal, Simulation, Static etc.

\section{Introduction}

Micromilling machines come under ultra precision machines. Such machine includes intricate and complex components. Performance of a micromilling machine depends upon various parameters like speed; feed. Holding of workpiece and (fixture) positioning it on table slide and feeding of table. It's the table and slides that governs the performance obtained from such systems. Machine table is one of the important components of micro-milling machine. Hence, there is scope and need to investigate its effect on machining accuracy. The table is complex and subjected to different loadings. In view of this the main purpose of this work, is to carry out analysis of table for micro milling. Tables (carriage) and slides are available in the international market in the standard sizes. In most the linear motion guides are used for accurate linear movements. Finite Element Analysis of Micromilling table is carried out on Static Stress Analysis (Von Mises Analysis), Dynamic Analysis and Modal Analysis to evaluate the response of micromilling table.

\section{Selection of linear motion slides}

Linear motion slides are available in international market, here available linear motion slide catalogue of "HepcoMotion" machine tools are used for making the cad model with the all specification of linear motion slide of table.

\section{Geometric Input for Linear Guide System}

"HepcoMotion" Simple-Select offers four useful sizes of spacer slides complete with carriages assembled ready for installation. All units are fitted with double row bearings and cap seals to ensure a long and trouble-free life. Their general purpose spacer slide precision cold drawn and hardened on the Vee running surfaces provides good accuracy and long life, even in the most hostile environment. Fig.1 shows 3D view linear motion slide of HepcoMotion. Fig.2 shows typical linear motion slide terminology from "HepcoMotion". 


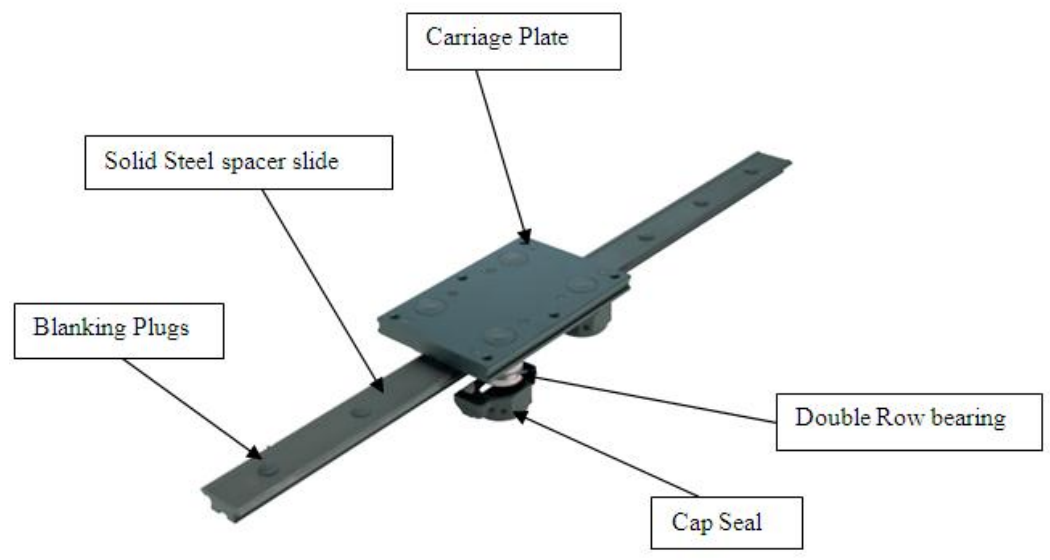

Fig.13D view linear motion slide [3]

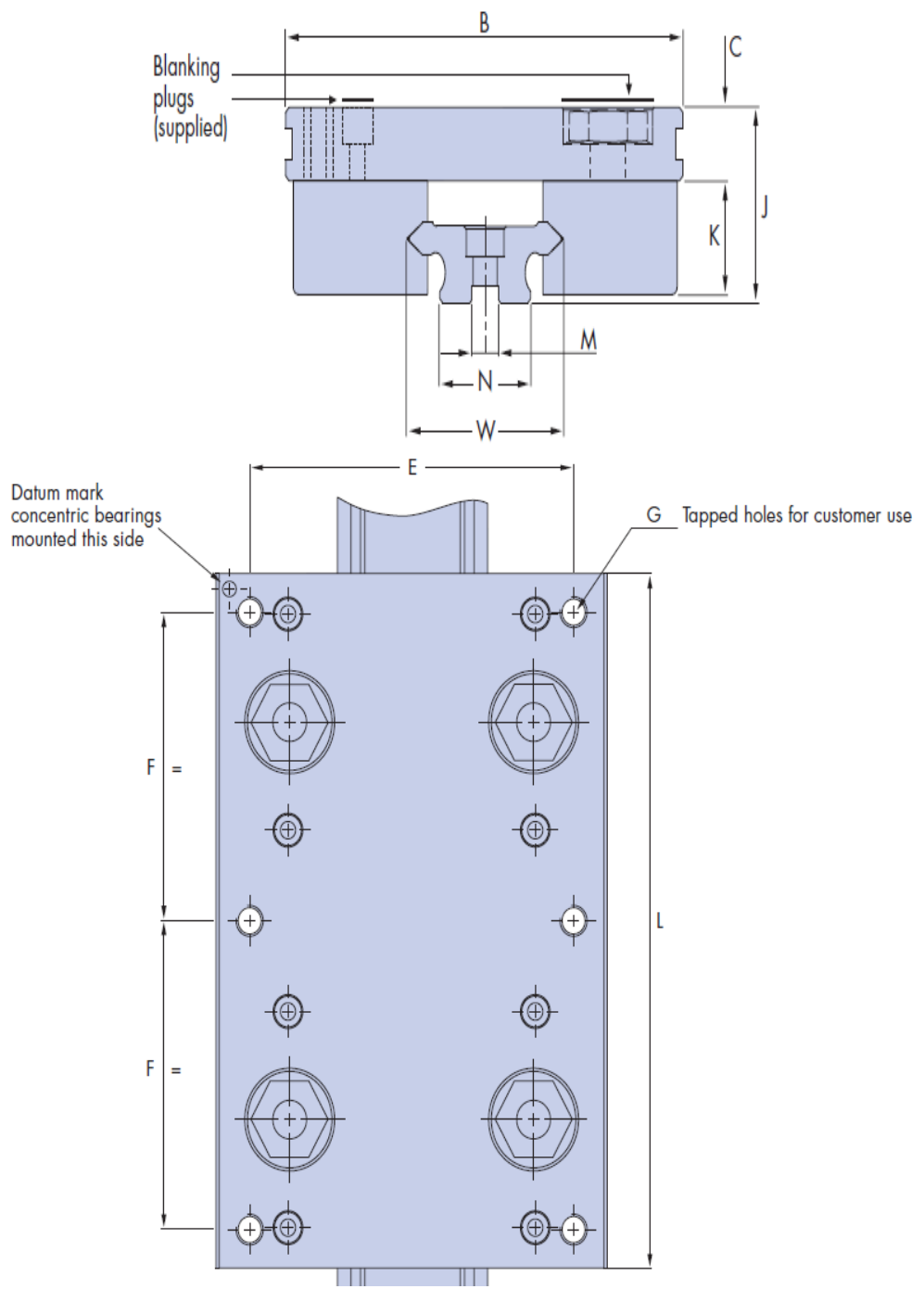

Fig. 2 Linear Motion slide Terminology [3]

Table 1 Geometric Input for Linear Guide System [3]

\begin{tabular}{|c|c|c|c|c|c|c|c|c|c|c|c|}
\hline Size & W & B & C & J & K & L & M & N & E & F & G \\
\hline 25 & 25 & 80 & 11.5 & 30.7 & 18 & 135 & $6 \times 2.5$ & 15.4 & 65 & 60 & 6 X \\
M6
\end{tabular}




\section{Modeling of Linear Motion Slide}

Modeling starts with 2D in CATIA.To create the CAD model of complete linear motion slide as per selected catalogue of HepcoMotion which has represents in fig.1 in the previous section. This model contains Double Edge Spacer Slide, Sealing Cap, Bearings, Carriage Unit, etc. The overall dimensions of linear guide are taken as per table 1 of previous section. Individual components such as slide, sealing cap, carriage, etc have been created and then assembled to create assembly in CATIA. Fig.3 shows the assembly of linear motion slide, which is hereafter refered as Micromilling Table.

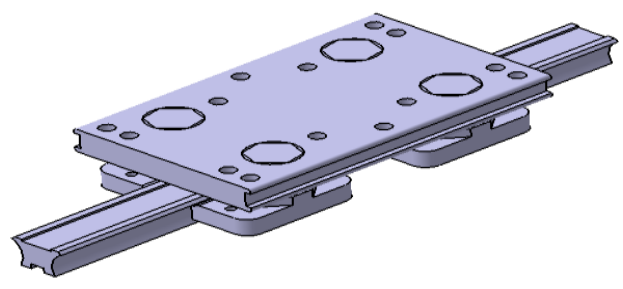

Fig. 3 Assembly of Linear Motion slide

\section{Analysis of Micromilling Table}

Analysis of Micromilling Table is carried out on following three important aspects of analysis to evaluate the response.

\subsection{Static Stress Analysis (Von Mises Analysis)}

\subsection{Dynamic Analysis}

5.3 Modal Analysis

5.1 Static Stress Analysis (Von Mises Analysis)

\subsubsection{Finite Element Analysis of Micro-Milling Table}

Finite element method is an excellent tool to analyze complex structures like Linear Motion Guide System by using computer which can help to reduce time and cost required for prototyping. Additionally, computer based designs can provide better solutions.

\subsubsection{Importing of CAD Model}

CAD model of assembly of micromilling table (Linear Motion Slide) is as shown in Fig. 3 and is created using CATIA as discussed in section 4. Fig.4 shows imported CAD model in ANSYS with 3D view.

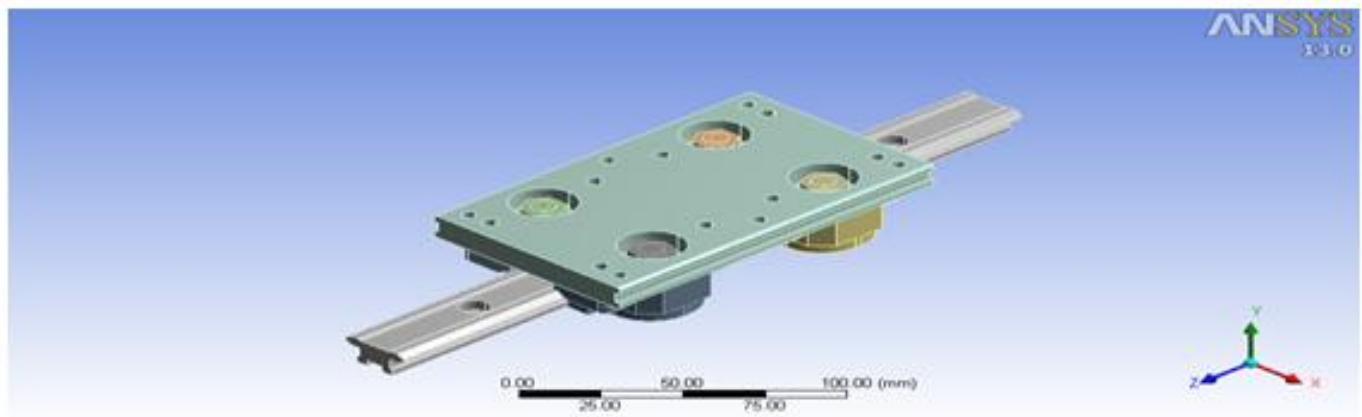

Fig. 4 3D CAD Model of Micromiling Table Imported in ANSYS

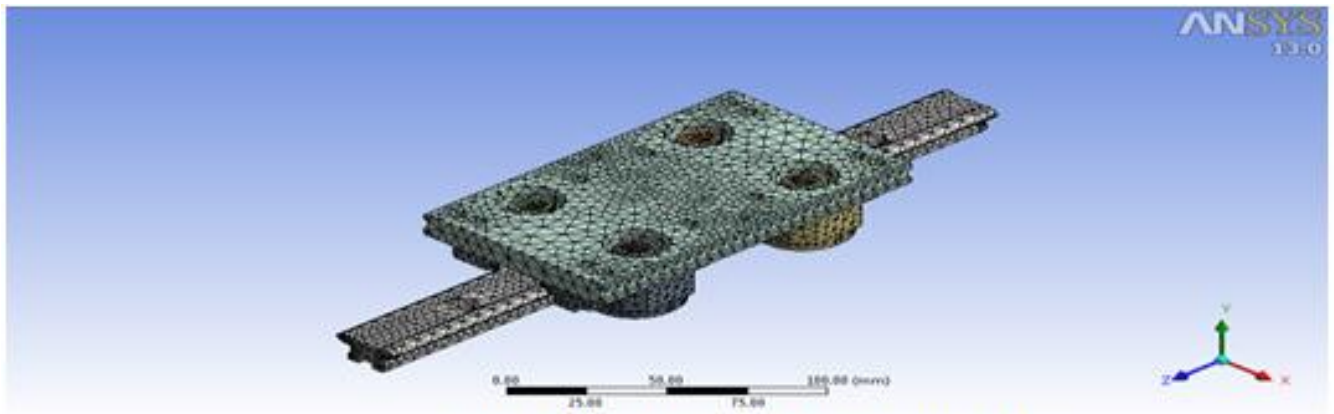

Fig. 5 Meshed model of Micromilling Table 


\subsubsection{Mesh Generation}

Meshing is nothing but converting a whole geometry into number of elements and these elements are connected by nodes. Linear Motion slide is meshed with tetrahedral solid elements of ANSYS. Tetrahedral SOLID element used in meshing of linear guide system. It has a quadratic displacement behavior and is well suited to modeling irregular meshes (such as those produced from various CAD/CAM systems).The element is defined by 04 nodes having three degrees of freedom at each node: translations in the nodal $\mathrm{x}, \mathrm{y}$, and $\mathrm{z}$ directions. Solid 185 elements used to mesh the geometry with element size $5 \mathrm{~mm}$. Total 87592 elements are generated with number of nodes 21692. Meshed model is as shown in fig.5.

\subsubsection{Material properties}

Table 2 shows the mechanical properties of various components used in micro-milling table. These properties are used for FE analysis in ANSYS.

Table 2 Material Properties

\begin{tabular}{|c|c|c|c|c|}
\hline Material Properties & Space Slide & Carriage & Bearing & Sealing Cap \\
\hline Material & $\begin{array}{c}\text { High carbon bearing } \\
\text { steel } \\
\text { AISI } 52100\end{array}$ & $\begin{array}{l}\text { High Strength } \\
\text { Aluminum Alloy }\end{array}$ & $\begin{array}{l}\text { Carbon-chromium } \\
\text { bearing steel } \\
\text { AISI } 52100\end{array}$ & $\begin{array}{c}\text { Thermoplastic } \\
\text { elastomer }\end{array}$ \\
\hline Chemical Composition & $\begin{array}{c}\mathrm{C}=0.95-1.05 \% \\
\mathrm{Cr}=1.30-1.65 \% \\
\mathrm{Si}=0.15-0.35 \% \\
\mathrm{Mn}=0.25-0.45 \%\end{array}$ & $\begin{array}{l}\mathrm{Zn}=5.6-6.1 \% \\
\mathrm{Mg}=2.1-2.5 \% \\
\mathrm{Cu}=1.2-1.6 \%\end{array}$ & $\begin{array}{c}\mathrm{C}=0.95-1.05 \% \\
\mathrm{Cr}=1.30-1.65 \% \\
\mathrm{Si}=0.15-0.35 \% \\
\mathrm{Mn}=0.25-0.45 \%\end{array}$ & $\begin{array}{c}\text { Thermoplastic } \\
\text { rubbers }\end{array}$ \\
\hline Young's Modulus (MPa) & $2.10 \times 10^{5}$ & $73.1 \times 10^{3}$ & $2.10 \times 10^{5}$ & 110 \\
\hline Poisson's ratio & 0.3 & 0.33 & 0.3 & 0.45 \\
\hline Density $\left(\mathrm{Kg} / \mathrm{m}^{3}\right)$ & 7850 & 2810 & 7850 & 924 \\
\hline Yield Strength (MPa) & 2033 & 580 & 2033 & 60 \\
\hline
\end{tabular}

\subsubsection{Loads Boundary Conditions (LBC's)}

In FEA, before doing the analysis of any structure, defining boundary conditions is a necessary thing. In the boundary conditions, base of the milling table was fixed. To carry out FE analysis of linear motion slide used in micro-milling table, slide ends are fixed, see blue color in Fig. 6. Fx and Fy [4] are applied on carriage. Fig. 6 shows typical arrangement of loads and boundary conditions on Micromilling Table in ANSYS.

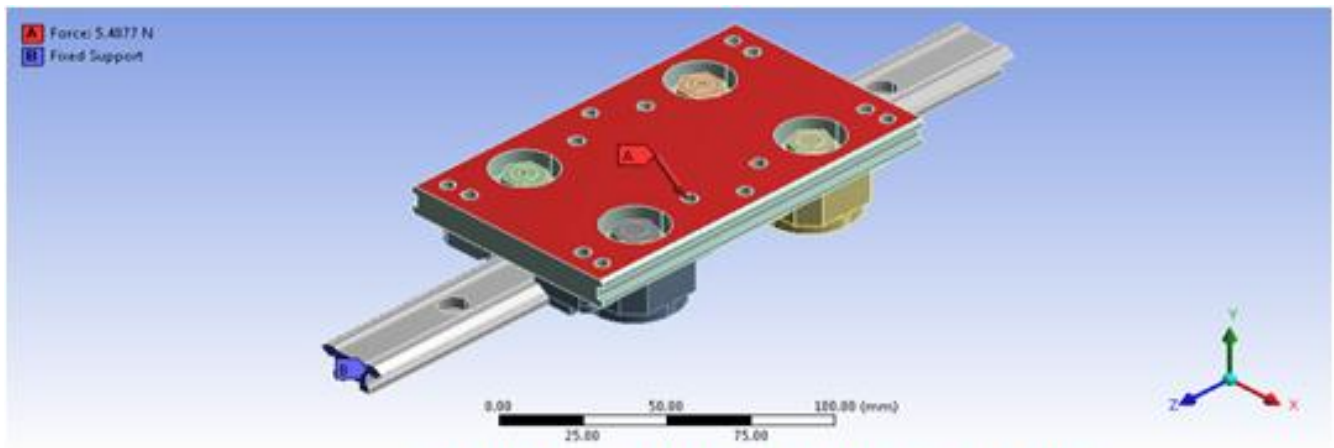

Fig. 6 Model with loads and boundary conditions

\subsubsection{Post-processing of stress results}

Postprocessing involves the review of various results such as stresses and deformations. Fig. 7 shows stresses in Micromilling Table. From results it appears that maximum stress is around 1MPa. This stress is much below yield limit of material. 


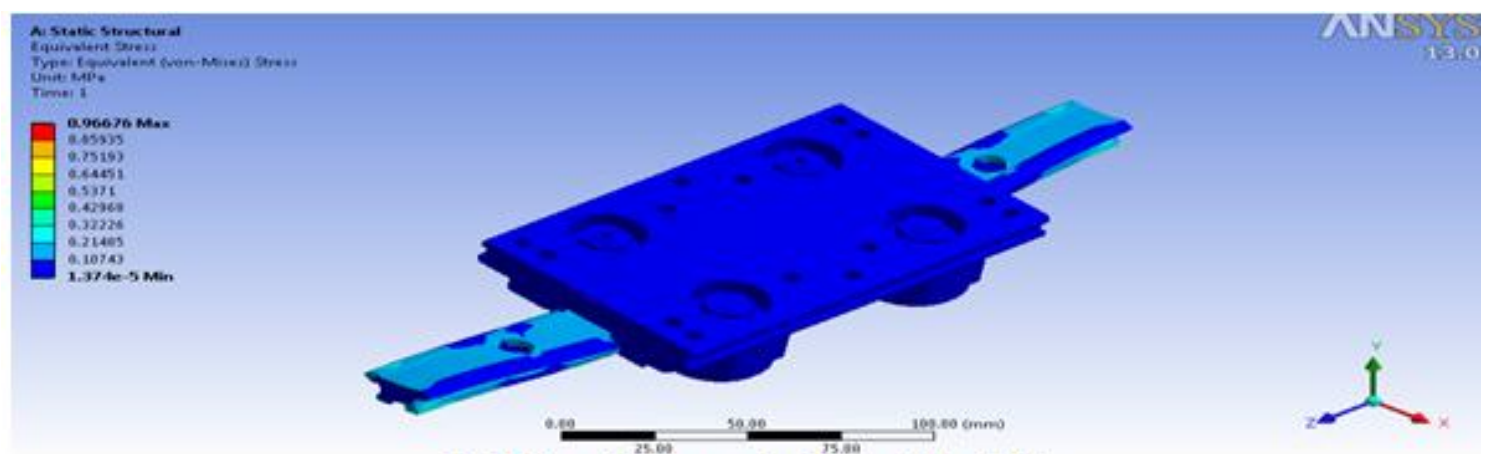

Fig. 7 Von Mises stress in Micromilling Table

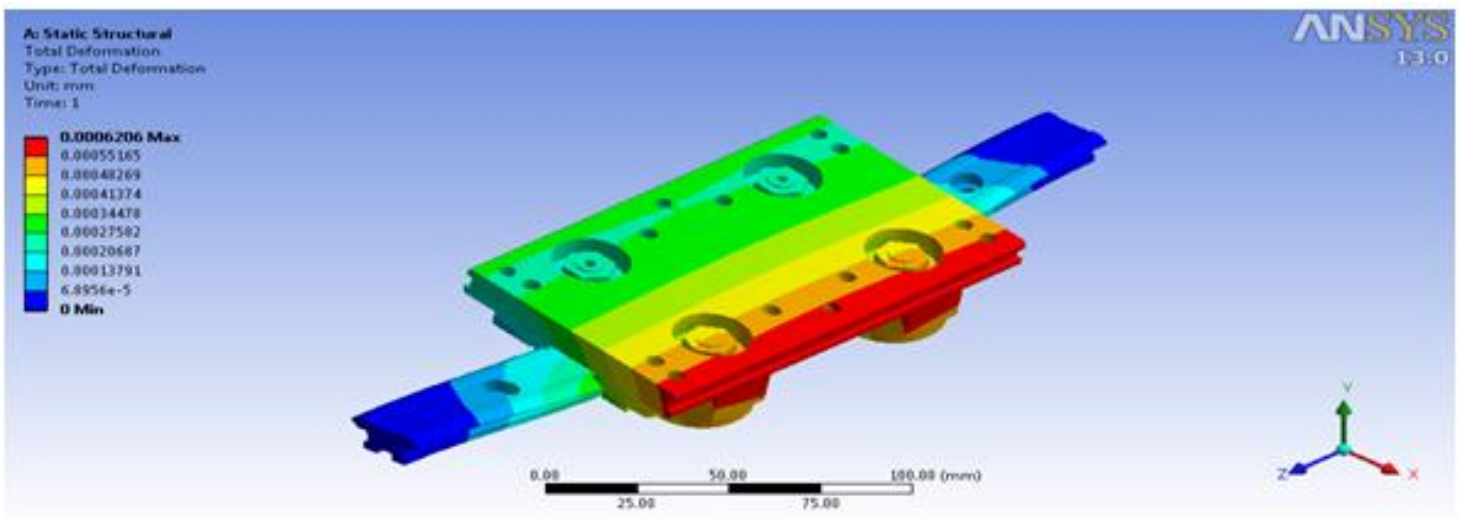

Fig. 8 Deformation in Micromilling Table

Fig. 8 shows the deformation in micromilling table. The maximum deformation is $0.6 \mu \mathrm{m}$ (i.e less than $1 \mu \mathrm{m})$ which is below the accuracy limit of table.

\subsection{Dynamic Analysis}

In this dynamic analysis of Micromilling Table, time incremental harmonic response analysis has been carried out. Response of Micromilling Table during harmonic response analysis has been obtained for, Amplitude vs. Frequency, Amplitude vs. Compliance, Effect of increasing cutting force within a range $1 \mathrm{~N}-2.5 \mathrm{~N}$ [5], Effect of increasing and decreasing stiffness value with respect to amplitude and frequency has been obtained.

A frequency range from $36 \mathrm{~Hz}$ to $500 \mathrm{~Hz}$ with $30 \mathrm{~Hz}$ intervals was chosen so as to give an adequate response curve. In this analysis, the machine structure was excited by a series of harmonic forces $\mathrm{F}$ ranging from $1 \mathrm{~N}-2.5 \mathrm{~N}$ acting between workpiece and cutting tool. During the selected range of force $1 \mathrm{~N}-2.5 \mathrm{~N}$, the force has been varying by a step of $0.25 \mathrm{~N}$.

\subsubsection{Solution}

The given configuration of micromilling table linear guide system is solved using ANSYS with inputs discussed in above section.

\subsubsection{Post-processing results of Linear motion slide (micromilling table) at different parameters}

Fig.9 shows Amplitude in X direction Vs Frequency under dynamic loading conditions, the maximum amplitude is observed in direction $\mathrm{X}$ that for a cutting force range of $1 \mathrm{~N}-2.5 \mathrm{~N}$ is at same frequency of $116 \mathrm{~Hz}$. Maximum observed amplitudes of the assembly of micromilling machine table are $6.53 \mathrm{E}-08 \mathrm{~mm}$ is obtained by applying load of $1 \mathrm{~N}$ and amplitudes $1.63 \mathrm{E}-07 \mathrm{~mm}$ is obtained by applying $2.5 \mathrm{~N}$ load, which are within the acceptable limit $1 \mu \mathrm{m}$. 


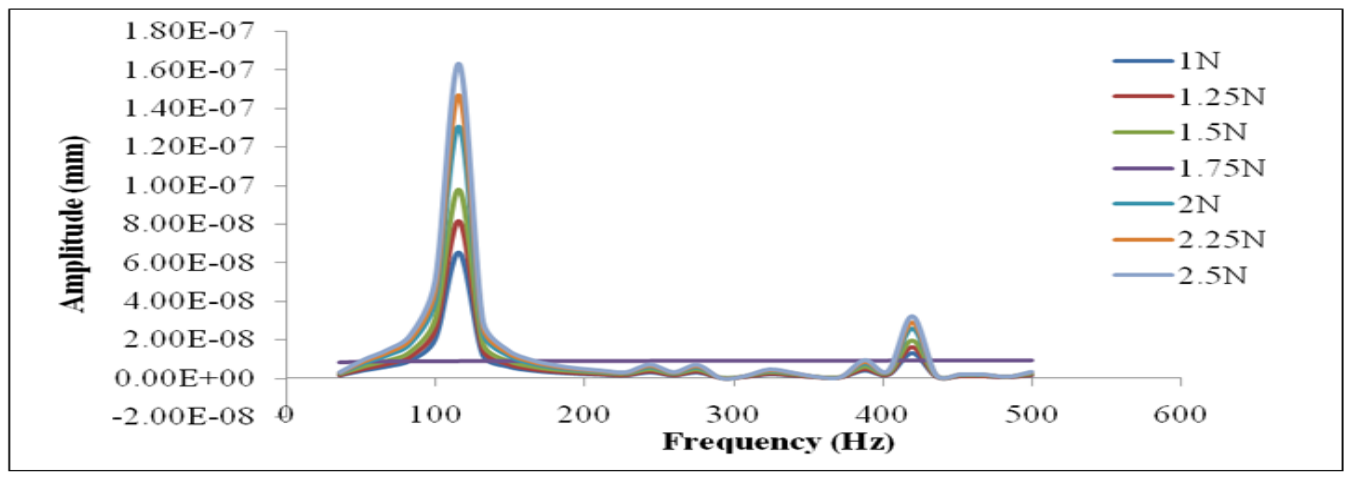

Fig. 9 Amplitude in $\mathrm{X}$ direction Vs Frequency

Fig.10 shows Compliance in $\mathrm{X}$ direction Vs frequency, under dynamic loading conditions, the maximum compliance is observed in direction $X$ that $5.79 \mathrm{E}-03 \mathrm{~mm} / \mathrm{N} \mathrm{mm}$ is obtained by applying load of $1 \mathrm{~N}$ at frequency of $452 \mathrm{~Hz}$ and compliance $5.79 \mathrm{E}-03 \mathrm{~mm} / \mathrm{N} \mathrm{mm}$ is obtained by applying $2.5 \mathrm{~N}$ load at frequency of $452 \mathrm{~Hz}$, which are within the acceptable limit $1 \mu \mathrm{m}$.



Fig. 10 Compliance in $\mathrm{X}$ direction Vs Frequency

Fig.11 and fig.12 shows, Amplitude Vs Frequency and Compliance Vs Frequency with respect to dynamic stiffness range from $-30 \%$ to $+30 \%$ respectively. Micromilling machine table has given satisfactorily response for dynamic analysis and the range is established where amplitude and compliance can be reduce by changing the value of stiffness. The range of stiffness is in between $2.817 \mathrm{~N} / \mu \mathrm{m}(-10 \%)$ to $3.756 \mathrm{~N} / \mu \mathrm{m}(+20 \%)$ gives less value of amplitude at $500 \mathrm{~Hz}$ frequency, $-10 \%$ (decrease) and $+20 \%$ (increase) in dynamic stiffness is the zone where amplitude can be reduced. The range of stiffness is in between $2.817 \mathrm{~N} / \mu \mathrm{m}(-10 \%)$ to $3.756 \mathrm{~N} / \mu \mathrm{m}$ $(+20 \%)$ gives less value of compliance at $500 \mathrm{~Hz}$ frequency, $-10 \%$ (decrease) and $+20 \%$ (increase) in dynamic stiffness is the zone where compliance can be reduced.

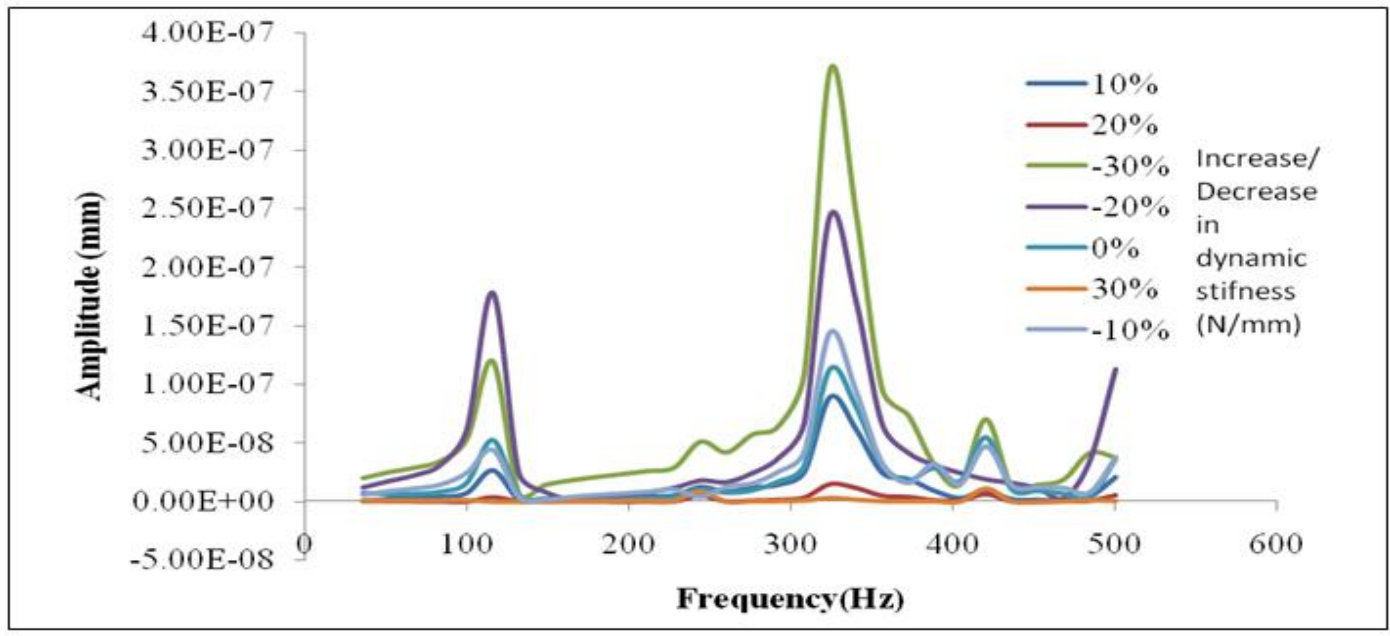

Fig.11 Amplitude Vs Frequency with respect to dynamic stiffness 


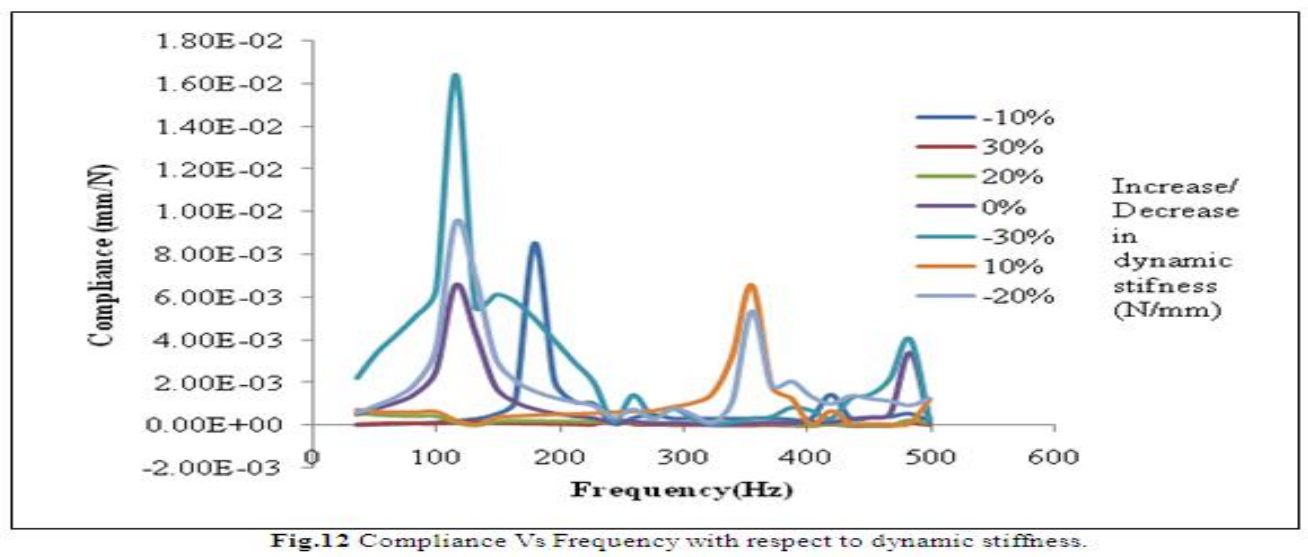

\subsection{Modal Analysis}

\subsubsection{Post-processing of Natural Frequency Analysis Results (Modal Analysis)}

Modal analysis is carried out in ansys workbench and various mode shapes are obtained along with its natural frequency. Modal analysis is carried out to know the different dead zones. Mode shapes will help to find out the exact regions of the dead zone on the structure where body will not naturally vibrate. Five nodes are extracted and corresponding dead zones are suggested. Table. 3 shows the first five natural frequencies of structure which are well below the operating speed of the structure.

Table.3 Natural frequency of Micromilling Table

\begin{tabular}{|c|c|}
\hline Mode Shape & Frequency[Hz] \\
\hline Mode Shape 1 & 40.71 \\
\hline Mode Shape 2 & 48.76 \\
\hline Mode Shape 3 & 105.94 \\
\hline Mode Shape 4 & 108.86 \\
\hline Mode Shape 5 & 113.009 \\
\hline
\end{tabular}

\section{Conclusion}

1. Maximum stress magnitude is near about $1 \mathrm{mpa}$ which is much below the yield limit of materials so the design is safe found irrespective of strength.

2. Maximum deformation is $0.6 \mu \mathrm{m}$ which is less than design accuracy $(1 \mu \mathrm{m})$ of micromilling table assembly and hence design is appropriate for micromilling machine table.

3. Micromilling machine table has given satisfactorily response for dynamic analysis and the range is established where amplitude as well as compliance can be reduce by changing the value of stiffness.

4. Modal analysis is carried out to identify the dead zones as well as the natural frequency of micromilling table.

5. Performance as well as accuracy of Micromilling machine can be enhances by obtained result of response of micromilling machine table under different affecting parameters.

6. Modal analysis gives the dead zones on micromilling table where frequency, amplitude and compliance are negligible. Those zones are very safe zones. Finding the dead zones are necessary is to improve the design in remaining regions of micromilling machine table. That can be done through the following,

- Change in the desired properties of the material of micromilling machine table.

- Change the design of micromilling machine table in topological (size, shape etc) aspects, etc.

\section{Acknowledgements}

We are very much thankful to our management, principal, HOD for boosting and promoting us for the research oriented works.

\section{References}

[1]. N K Mehta, "Machine Tool Design and Numerical Control”, pp167-168, pp178-187 and pp215-219.

[2]. V B Bhandari, "Design of machine Elements", pp58-pp60.

[3]. http://www.hepcomotion.com/en/simple-select-vee-bearing-linear-motion-guide-pg-14-get-2

[4]. Shih-Ming Wang, Zou-Sung Chiang, Da-Fun Chen and Yao-Yang TSAI, "A New Cutting Force Model for Micro-milling and Determination of Optimal Cutting Parameters", Advanced Materials Research,vols.83-86,2009, pp680-687.

[5]. Cheng-Zhe Jin, Ik-Soo Kang, Jin-Hyo Park, Su-Hoon Jang and Jeong-Suk Kim. "The characteristics of cutting forces in the micromilling of AISI D2 steel”, Journal of material science and technology, 2009. 